\title{
In Vitro Analog of Operant Conditioning in Aplysia. II. Modifications of the Functional Dynamics of an Identified Neuron Contribute to Motor Pattern Selection
}

\author{
Romuald Nargeot, Douglas A. Baxter, and John H. Byrne \\ Department of Neurobiology and Anatomy and W. M. Keck Center for the Neurobiology of Learning and Memory, The \\ University of Texas-Houston Medical School, Houston, Texas 77030
}

Previously, an analog of operant conditioning was developed using the buccal ganglia of Aplysia, the probabilistic occurrences of a specific motor pattern (i.e., pattern I), a contingent reinforcement (i.e., stimulation of the esophageal nerve), and monotonic stimulation of a peripheral nerve (i.e., n.2,3). This analog expressed a key feature of operant conditioning (i.e., selective enhancement of the probability of occurrence of a designated motor pattern by contingent reinforcement). In addition, the training induced changes in the dynamical properties of neuron B51, an element of the buccal central pattern generator. To gain insights into the neuronal mechanisms that mediate features of operant conditioning, the present study identified a neuronal element that was critically involved in the selective enhancement of pattern I. We found that bursting activity in cell B51 contributed significantly to the expression of pattern I and that changes in the dynamical properties of this cell were associated with the selective enhancement of pattern I. These changes could be induced by an explicit association of reinforcement with random depolarization of B51. No stimulation of n.2,3 was required. These results indicate that the selection of a designated motor pattern by contingent reinforcement and the underlying neuronal plasticity resulted from the association of reinforcement with a component of central neuronal activity that contributes to a specific motor pattern. The sensory stimulus that allows for occurrences of different motor acts may not be critical for induction of plasticity that mediates the selection of a motor output by contingent reinforcement in operant conditioning.

Key words: learning and memory; operant conditioning; contingent reinforcement; law of effect; central pattern generator; regenerative properties; buccal ganglia; Aplysia californica; B51
Operant conditioning is characterized by modification of the probabilistic occurrence of a designated behavior (i.e., operant) by contingent reinforcement (Thorndike, 1933; Fox and Rudell, 1968, 1970; Fetz and Finocchio, 1971; Skinner, 1981). Several distinct elements can be distinguished in this associative learning paradigm: (1) an emitted behavior or operant that is generated by the CNS, (2) a reinforcement that is contingent on the occurrence of a designated behavior, and in some cases, (3) a stimulus that provides the occasions on which a designated behavior and reinforcement are associated (Rescorla, 1987). Although reinforcement is critical for operant conditioning (Bolles, 1972; Rescorla, 1987; Vaccarino et al., 1989), a fundamental question is whether reinforcement strengthens the ability of a stimulus to elicit a behavior or whether the stimulus plays a secondary role in learning and changes to the operant result primarily from the association of reinforcement with central neuronal processes that organize emitted behaviors (Hull, 1943; Tolman, 1949; Rescorla, 1987; Mowrer and Klein, 1989).

\footnotetext{
Received July 27, 1998; revised Dec. 1, 1998; accepted Dec. 30, 1998.

The research was supported by the Ernst Knobil Fellowship, Air Force Office of Scientific Research Grant F620-97-1-0049, Grant 011618-048 from the Texas Higher Education Coordinating Broad, National Institute of Mental Health (NIMH) Grant R01 MH58321, and NIMH Award K05 MH00649. We thank F. D. Lorenzetti for rescoring the data using a blind procedure.

Correspondence should be addressed to Dr. John H. Byrne, Department of Neurobiology and Anatomy, The University of Texas Medical School at Houston, P.O. Box 20708, Houston, TX 77225.

Dr. Nargeot's present address: Université Bordeaux I, Laboratoire de Neurobiologie des Réseaux, Bât. Biologie Animale-B2, Avenue des Facultés, 33405 Talence, Cedex, France.

Copyright (C) 1999 Society for Neuroscience $\quad 0270-6474 / 99 / 192261-12 \$ 05.00 / 0$
}

The latter hypothesis, which does not implicate the stimulus in learning, corresponds more closely to the procedure that defines operant conditioning (i.e., the association between reinforcement and occurrences of a designated behavior) (Mackintosh, 1974). Moreover, the contingent-dependent modification of a selective behavior rather than all those induced by a given stimulus may indicate that the stimulus is not critical for learning (Skinner, 1966). If so, it is important to identify the processes that govern the probabilistic occurrences of specific behaviors and determine whether the interaction of reinforcement with these processes induces neuronal changes that could underlie the selective enhancement of a designated behavior. To gain insights into the neuronal mechanisms that determine characteristic features of operant conditioning, we investigated the elements that are critical to the induction of the neuronal changes mediating the selective enhancement of a designated motor output.

We used an analog of operant conditioning that was previously developed in the isolated buccal ganglia of Aplysia (Nargeot et al., 1997b). In this analog, monotonic stimulation of the peripheral nerve 2,3 (n.2,3) was used to induce different motor patterns that were similar to those recorded in vivo during feeding behaviors. Contingent reinforcement of a specific buccal motor output (i.e., pattern I) enhanced the occurrence of this pattern and modified the intrinsic properties of an identified neuron (i.e., B51) in the buccal central pattern generator (CPG) [see accompanying article in this issue (Nargeot et al., 1999a)]. In the present study, we investigated whether plasticity in B51 may be related to the selective enhancement of pattern I. The results indicated that changes in intrinsic membrane properties of B51, which were 
induced by contingent reinforcement but independent of the monotonic stimulation of n.2,3, contribute to the key feature of operant conditioning.

Preliminary reports of these results have been published previously in abstract form (Nargeot et al., 1997a, 1998)

\section{MATERIALS AND METHODS}

The methods for preparing the isolated buccal ganglia, inducing the rhythmic motor patterns, recording extracellular and intracellular activity, and analyzing data are described in the accompanying article [Nargeot et al. (1999a); also see Nargeot et al. (1997b)]. The method used to define the different motor patterns was identical to that described in detail in our companion paper (Nargeot et al., 1999a). This method was based on the proportion of large-amplitude bursting activity (i.e., closure motor activity) recorded in the radula nerve 1 (i.e., $\mathrm{R} \mathrm{n.} \mathrm{1)} \mathrm{that} \mathrm{occurs}$ after the protraction phase of the pattern (i.e., during the retraction phase) as monitored by termination of bursting activity in the nerve to intrinsic muscle 2 (i.e., I2 n.) (see Fig. 1).

In the present study, chemical synaptic connections were examined for a one-for-one relationship between presynaptic action potentials and postsynaptic potentials (PSPs) in presence of artificial seawater (ASW) and then in modified ASW in which $\mathrm{CaCl}_{2}$ was replaced by $\mathrm{CoCl}_{2}(10$ $\mathrm{mM}$ ), a solution that blocks chemical synapses. Monosynaptic connections were defined as those PSPs with a constant delay and a one-for-one relationship between presynaptic action potentials and PSPs in both ASW and in modified ASW that had higher concentrations of divalent ions (i.e., the concentration of $\mathrm{CaCl}_{2}$ was raised to $30 \mathrm{~mm}$ and the concentration of $\mathrm{MgCl}_{2}$ was raised to $165 \mathrm{~mm}$ ) (Byrne et al., 1978). Electrical synaptic connections were tested by injection of depolarizing and hyperpolarizing current pulses into the cell bodies in the presence of the solution that blocks chemical synapses (see above). Membrane properties were tested as described in the accompanying article (Nargeot et al., 1999a).

\section{RESULTS}

\section{Activity of B51 was associated with the occurrence of pattern I}

Different buccal motor patterns (i.e., pattern I, pattern II, and intermediate patterns) similar to those recorded in vivo during consummatory feeding behaviors can be induced in the isolated buccal ganglia by monotonic $(4 \mathrm{~Hz}$ ) electrical stimulation of n.2,3 (Nargeot et al., 1997b) (Fig. 1). These patterns are composed of a protraction phase (i.e., activity in $\mathrm{I} 2 \mathrm{n}$.) immediately followed by a retraction phase (i.e., activity in n.2,1; see Fig. 9) and closure activity (i.e., large-amplitude activity in R n.1 that represents the firing of the four B8 closure motor neurons). The different motor patterns were distinguished by the phase relationship of the large-amplitude bursting activity in R n.1 relative to the protraction and retraction phases (Morton and Chiel, 1993).

In pattern I (i.e., ingestion-like pattern), at least $50 \%$ of the total large-amplitude bursting activity in $\mathrm{R} \mathrm{n.1}$ occurred during the retraction phase (Fig. 1). In pattern II (i.e., egestion-like pattern), this activity occurred only during the protraction phase of the pattern (Fig. 1). In intermediate patterns, the largeamplitude bursting activity in $\mathrm{R} n .1$ extended beyond the protraction phase, but $<50 \%$ of this activity occurred during the retraction phase. These patterns also were associated with differences in the duration of the retraction phase. The duration of the retraction phase was longer in pattern I than either in pattern II or in intermediate patterns and was longer in intermediate patterns than in pattern II (Nargeot et al., 1999a).

The dynamics of the occurrences of the different motor patterns were correlated with the dynamics of activity in neuron B51 (Fig. 1) (Nargeot et al., 1999a). Bursting activity in B51 (i.e., activity of $>4 \mathrm{~Hz}$ and for $>1 \mathrm{sec}$ ) was associated with occurrences of pattern I. Less activity in B51 (i.e., activity lower than $4 \mathrm{~Hz}$ or

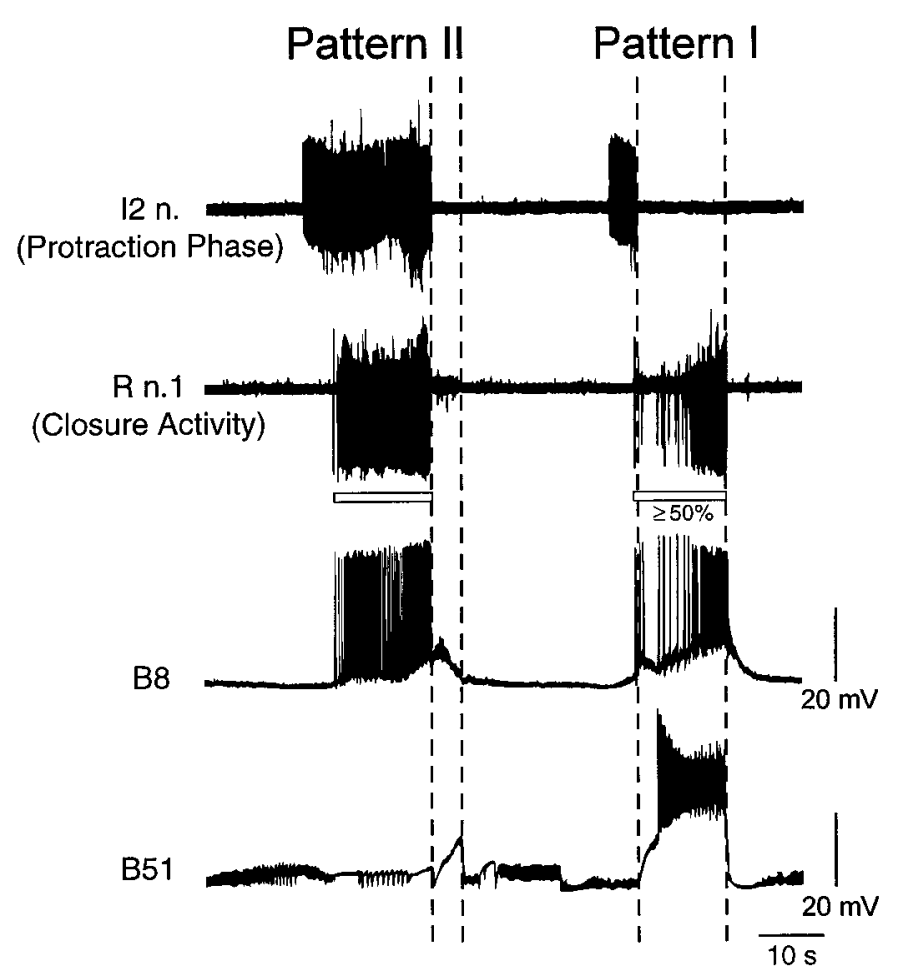

Figure 1. Pattern-specific activity in B51. At least two types of rhythmic motor patterns (e.g., pattern I and pattern II) were induced by monotonic $(4 \mathrm{~Hz})$ stimulation of n.2,3. Both types of patterns were composed of a protraction phase, monitored as activity in $\mathrm{I} 2 \mathrm{n}$., followed by a retraction phase; dashed vertical lines indicate the duration of the retraction phase that was monitored by activity in n.2,1 (this activity was not shown to simplify this and the following figures). In Pattern II, the closure motor activity (i.e., large-amplitude activity in $\mathrm{R} \mathrm{n} .1$ corresponding to activity in the closure motor neurons B8; horizontal bars) occurred during the protraction phase. In Pattern I, the closure motor activity (horizontal bar) primarily (at least 50\%) occurred during a prolonged retraction phase (compare with the retraction phase of pattern II). During rhythmic motor patterns, switching between different patterns occurred with no predictable frequencies but was correlated with switching between inactive (i.e., in pattern II) and bursting states in B51 (i.e., in pattern I). The bursting state of B51 (i.e., activity higher than $4 \mathrm{~Hz}$ for $>1 \mathrm{sec}$ ) was primarily associated with the occurrences of pattern I.

for $<1 \mathrm{sec})$ was associated with occurrences of intermediate patterns (Nargeot et al., 1999a). Finally, inactivity of B51 was associated with occurrences of pattern II. Activity in B51 was found not to be a determining factor for the expression of pattern II and was not a sufficient factor for the expression of features of intermediate patterns (Nargeot et al., 1999a). In contrast, B51 firing predicted features of pattern I such as the duration of the retraction phase and the duration of closure activity occurring during the retraction phase (Nargeot et al., 1999a). These observations raised the possibility that B51 may play an important role in the expression of pattern I.

\section{B51 contributes to features of pattern I}

To investigate the role of B51 in the expression of pattern I, we used three groups of 11 preparations in which we attempted to modify the occurrences of pattern I by experimental manipulations of the activity in B51. In all preparations, monotonic stimulation of n.2,3 was delivered for 20 min to induce the rhythmic motor pattern. In a depolarized group, B51 was depolarized by current pulses of an intensity above the threshold to elicit bursting activity in the cell (i.e., 7-10 nA). In a hyperpolarized group, B51 
was hyperpolarized by current pulses sufficient to suppress activity in B51 (i.e., -10 to $-17 \mathrm{nA}$ ). In a control group, activity in B51 was not experimentally manipulated. Because B51 was active during the retraction phase of patterns, in the depolarized and the hyperpolarized groups, B51 firing was manipulated only during this phase. The current pulses were turned on at the termination of activity in $\mathrm{I} 2 \mathrm{n}$. (i.e., at the beginning of the retraction phase) and turned off $\sim 1 \mathrm{sec}$ after termination of activity in n.2,1. These current pulses were delivered during all ongoing motor patterns.

Such procedures significantly modified the proportions of patterns in which $\mathrm{B} 51$ was active or inactive $(H=28.446$; $\mathrm{df}=2 ; p<$ $0.001)$. The proportion of patterns in which B51 was active was significantly higher in the depolarized group than either in the control $\left(q_{2}=5.154 ; p<0.001\right)$ or in the hyperpolarized group $\left(q_{3}\right.$ $=7.343 ; p<0.001)$. It was also higher in the control group than in the hyperpolarized group $\left(q_{2}=5.781 ; p<0.001\right)$. Thus, these procedures could reliably modify firing in B51 and thereby could be used to determine the effects of B51 firing on the expression of the motor patterns.

Examples of the recordings of the motor patterns in a depolarized preparation and in a hyperpolarized preparation are illustrated in Figure 2. When B51 was depolarized during the retraction phase of motor patterns, most of these patterns expressed the features of pattern I (Fig. $2 A$ ) [i.e., the closure activity recorded in $\mathrm{R} \mathrm{n.1}$ or in the closure motor neurons (B8) primarily occurred during a prolonged retraction phase]. In contrast, when $\mathrm{B} 51$ was hyperpolarized, the closure motor activity recorded in $\mathrm{R}$ $\mathrm{n} .1$ or in $\mathrm{B} 8$ did not extended sufficiently into the retraction phase to express the feature of pattern I (Fig. 2B). Moreover, the duration of the retraction phase of these patterns was shorter than the duration of the retraction phase of patterns in depolarized preparations. Thus, hyperpolarization of B51 decreased the occurrences of pattern I, and the rhythmic motor activity induced in these preparations was mainly composed of pattern II and intermediate patterns.

These effects of B51 on the expression of pattern I were supported by statistical comparison of the rhythmic motor patterns induced in the three groups of preparations (Fig. $3 A$ ). The frequency of occurrences of pattern I recorded during the $20 \mathrm{~min}$ period was significantly different among the groups of preparations $(H=7.579$; df $=2 ; p<0.02)$. Post hoc pairwise comparisons indicated that a higher number of occurrences of pattern I were expressed in the group in which B51 was depolarized than either in the control group $\left(q_{2}=2.856 ; p<0.05\right)$ or in the group in which B51 was hyperpolarized $\left(q_{3}=3.882 ; p<0.025\right)$. Moreover, the occurrences of pattern I were lower in the group in which B51 was hyperpolarized than in control group $\left(q_{2}=2.925\right.$; $p<0.05)$. These results indicate that activity in B51 was a major factor contributing to features of pattern I.

In those experiments in which B51 was forced to fire during all motor patterns, the expression of pattern II was also significantly modified $(H=16.745$; df $=2 ; p<0.001)$. The frequency of occurrences of pattern II was decreased in preparations in which B51 was depolarized $(0.09 \pm 0.03 / \mathrm{min}$; mean $\pm \mathrm{SEM})$ as compared with either preparations in which B51 was hyperpolarized $\left(0.48 \pm 0.08 / \mathrm{min} ; q_{3}=5.753 ; p<0.001\right)$ or control preparations $\left(0.24 \pm 0.07 / \mathrm{min} ; q_{2}=4.109 ; p<0.005\right)$. Moreover, occurrences of pattern II were significantly increased when B51 was hyperpolarized as compared with the control activity $\left(q_{2}=4.457 ; p<\right.$ $0.005)$. These modifications were opposite to the effect on pattern I. Although B51 was usually silent during pattern II and thus
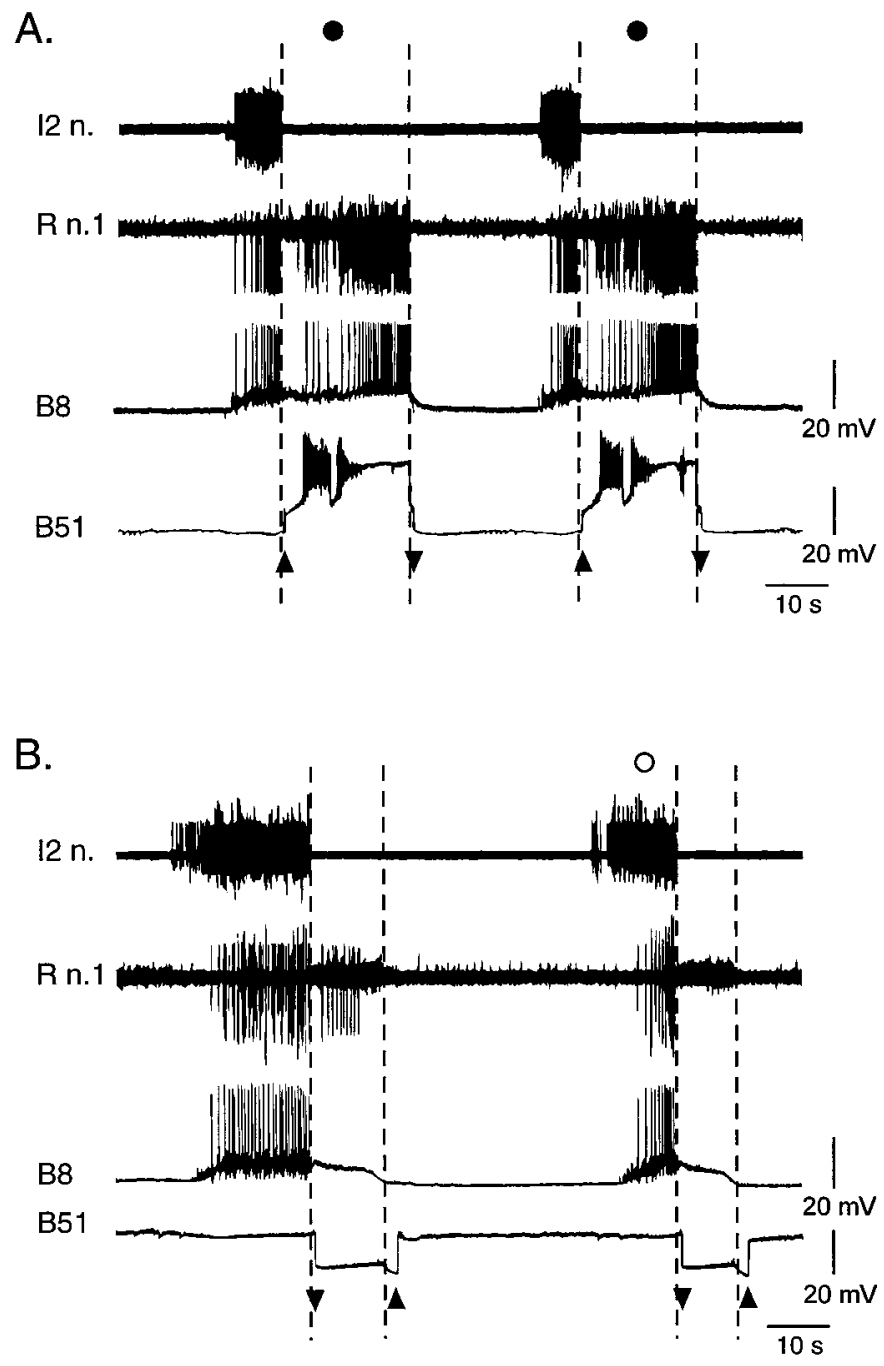

Figure 2. Activity in B51 elicited features of pattern I. $A$, During rhythmic motor patterns induced by monotonic stimulation of n.2,3, experimental depolarization of B51 (up and down arrowheads indicate the onsets and offsets, respectively, of current pulses) in the retraction phases of the patterns (dashed vertical lines indicate the duration of the retraction phase) elicited the key features of pattern I $(\mathbf{O})$. B. Experimental hyperpolarization of B51 (down and up arrowheads indicate the onsets and offsets, respectively, of current pulses) during the retraction phase of the patterns (dashed vertical lines indicate the duration of the retraction phase) induced by monotonic stimulation of n.2,3 prevented the features of pattern I. The patterns expressed features of intermediate pattern and pattern II $(\bigcirc)$.

cannot be directly responsible for the expression of this pattern [Fig. 1; see also Nargeot et al. (1999a)], the experimental paradigms that imposed or suppressed firing of B51 in all types of motor patterns indirectly modified the frequency of occurrences of pattern II.

Finally, manipulations of activity in B51 had no significant effect on the frequency of occurrences of intermediate patterns $(H=3.952 ; \mathrm{df}=2$; control $0.50 \pm 0.12 / \mathrm{min}$; B51 depolarized, $0.38 \pm 0.08 / \mathrm{min} ;$ B51 hyperpolarized, $0.65 \pm 0.10 / \mathrm{min})$. This result is consistent with previous observations suggesting that cells other than B51 are important for the specific features of this pattern (Nargeot et al., 1999a).

These results indicate that during rhythmic motor activity induced by monotonic stimulation of n.2,3 and in absence of other 
A.
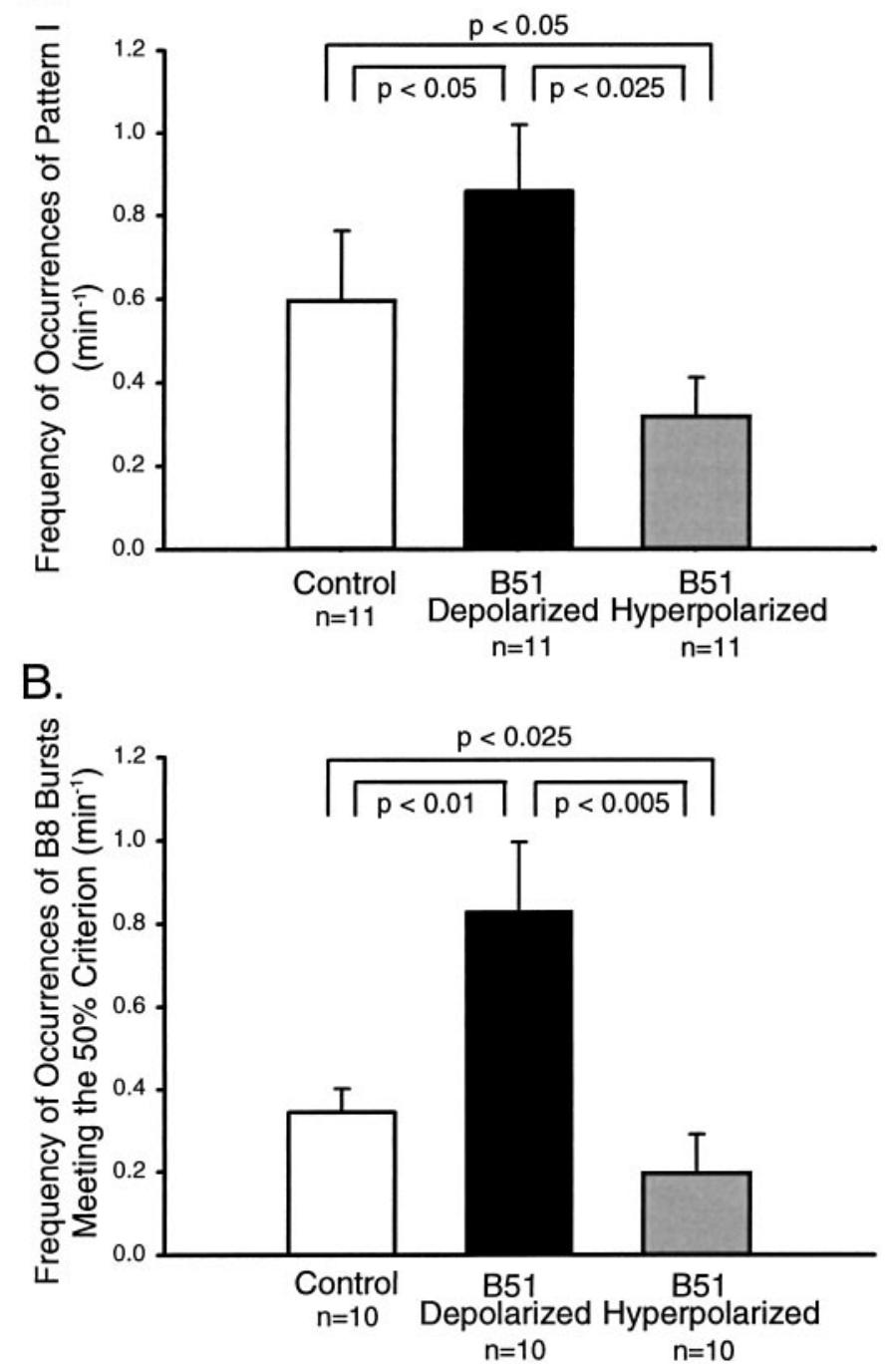

C.

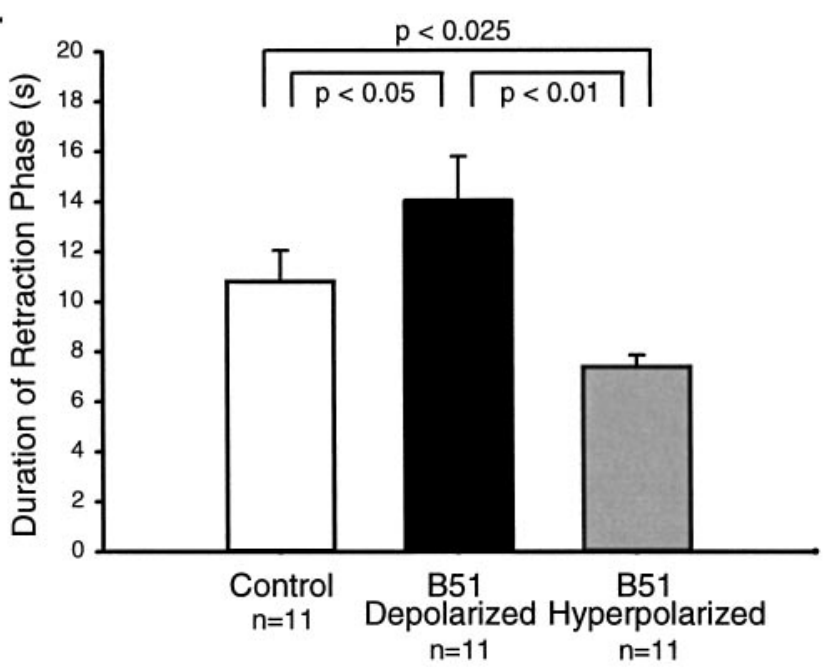

Figure 3. Neuronal modifications induced by manipulating activity in B51. The frequency of occurrences of pattern I $(A)$, the frequency of occurrences of patterns in which at least $50 \%$ of activity in a closure motor neuron $\mathrm{B} 8$ occurred during the retraction phase $(B)$, and the duration of the retraction phase of the patterns $(C)$ were calculated during a 20 min period of monotonic stimulation of n.2,3 in a control experimental manipulation, activity in B51 contributes to features of pattern I. Because pattern I is characterized by the occurrences of a closure motor activity during the retraction phase and by a long retraction phase, one would predict that the modification of occurrences of pattern I by manipulation of B51 firing could result from changes in the activity of the closure motor neurons B8 and in the duration of activity in n.2,1 that monitors the retraction phase.

The spike activity in both a closure motor neuron B8 and the ipsilateral B51 was recorded simultaneously. A comparison of the occurrences of activity in B8 that primarily (at least $50 \%$ ) overlapped with the retraction phase of the motor patterns was significantly different among the groups of preparations (Fig. $3 B$ ) $(H=11.309 ;$ df $=2 ; p<0.005)$. This activity occurred significantly more often in preparations in which B51 was depolarized than either in the control preparations $\left(q_{2}=3.688 ; p<0.01\right)$ or in the preparations in which B51 was hyperpolarized $\left(q_{3}=4.742\right.$; $p<0.005)$. Moreover, this activity was greater in the control preparations than in the preparations in which B51 was hyperpolarized $\left(q_{2}=3.367 ; p<0.025\right)$. Thus, firing B51 modified the activity in the closure motor neurons B8.

The duration of the retraction phase (i.e., activity in n.2,1 measured from the termination of activity in $\mathrm{I} 2 \mathrm{n}$.) (Nargeot et al., 1997b, 1999a) was also significantly different among the three groups of preparations (Fig. $3 C)(H=9.311$; df $=2 ; p<0.01)$. This activity was significantly longer in the preparations in which B51 was depolarized than either in the control preparations $\left(q_{2}=\right.$ 2.786; $p<0.05)$ or in the preparations in which B51 was hyperpolarized $\left(q_{3}=4.303 ; p<0.01\right)$. Finally, this duration was longer in the control preparations than in the preparations in which B51 was hyperpolarized $\left(q_{2}=3.622 ; p<0.025\right)$.

Thus, activity of B51 appears to control both the activity in the motor neurons B8 during the retraction phase and the duration of the retraction phase of patterns. We next investigated the mechanisms by which B51 mediates these effects. We tested for synaptic connections between B51 and B8 and between B51 and neuron B64, which elicits the retraction phase of the buccal motor patterns (Hurwitz and Susswein, 1996).

\section{Synaptic connections from B51}

To examine the synaptic connections made by B51, no stimulation of n.2,3 was used so that no rhythmic motor activity was induced. A brief (5 sec) current pulse injected into B51 can elicit a plateau potential in B51 (i.e., high-frequency activity that persists after the current pulse is terminated). Such activity depolarized and elicited spike activity in the ipsilateral B8. This excitation in B8 lasted as long as the activity in B51. In all preparations tested $(n=10)$, action potentials in B51 elicited EPSPs of $1-8 \mathrm{mV}$ in B8 that can be sufficient to drive spike activity in B8. The EPSPs in B8 appeared to be generated by a monosynaptic chemical connection from B51. The PSP occurred with a one-for-one relationship and with a constant delay $(6.7 \pm 0.8 \mathrm{msec} ; n=4)$ relative to

$\leftarrow$

group (i.e., in absence of experimental manipulation of activity in B51; white bars), and in groups of preparations in which B51 was either experimentally depolarized (black bar) or hyperpolarized (gray bar) during the retraction phase of each successive pattern. Manipulating the activity in B51 significantly modified the frequency of occurrences of pattern $\mathrm{I}(A)$. This modification was associated with changes in activity of B8 during the patterns $(B)$ and in the duration of the retraction phase of the patterns $(C)$. The B8 neurons recorded in 10 preparations of each group were ipsilateral to B51. 


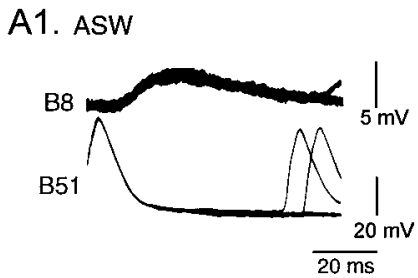

A2. High Divalent ASW
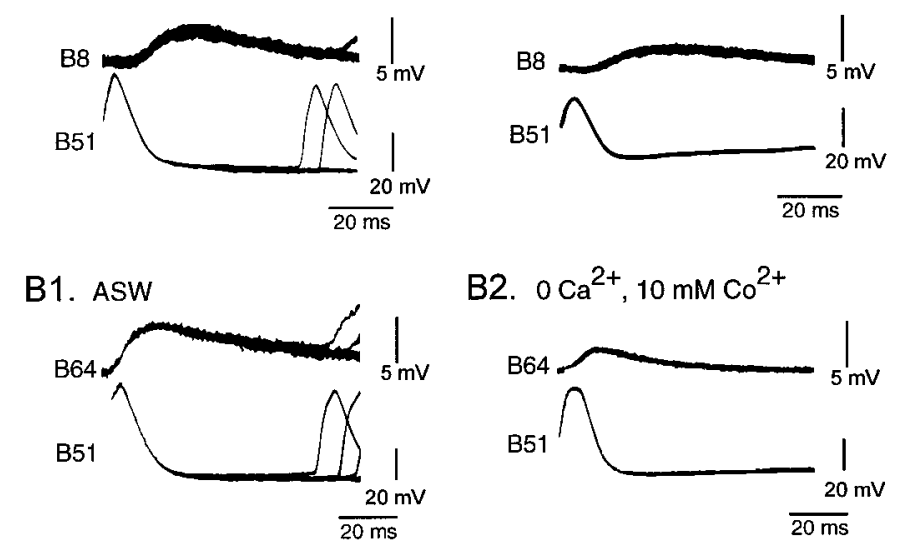

B2. $\mathrm{OCa}^{2+}, 10 \mathrm{mM} \mathrm{Co}^{2+}$

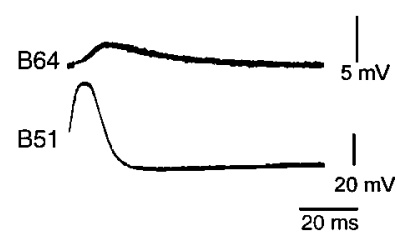

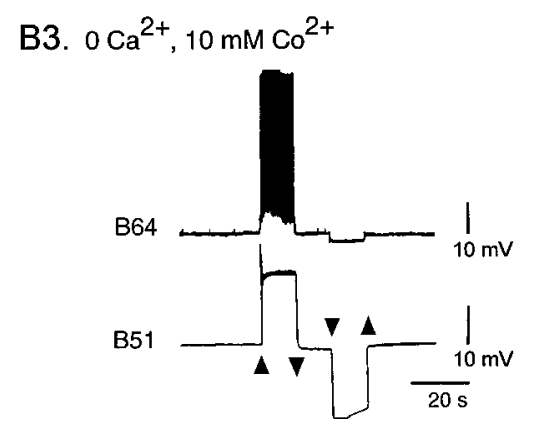

Figure 4. Synaptic excitation from neuron B51 to the closure motor neuron $\mathrm{B} 8$ and the retraction generator neuron $\mathrm{B} 64 . A$, $\mathrm{A}$ one-for-one relationship between action potentials in B51 and EPSPs in the ipsilateral B8 recorded both in artificial seawater $(A 1, A S W)$ and in high divalent ASW (A2) suggested a monosynaptic excitatory connection between B51 and the ipsilateral B8. Note that in high divalent solution, the amplitude of the EPSPs in B8 was reduced. This reduction in EPSP amplitude may be attributable to the corresponding decrease in the amplitude of the presynaptic spikes. Recordings in panels $\mathrm{A} 1$ and $\mathrm{A} 2$ were from the same preparation. Four traces were superimposed in each case. $B$, A one-forone relationship between action potentials in B51 and EPSPs in the ipsilateral B64 recorded in the presence of ASW (B1). In a solution used to block chemical synaptic connections (calcium was replaced with cobalt), the amplitude and shape of these EPSPs were modified but not suppressed, suggesting that B51 excited B64 with both chemical and electrical synapses $(B 2)$. Recording in $B 1$ and $B 2$ were from the same preparation in which membrane potential of B64 was held at $-60 \mathrm{mV}$. Six traces were superimposed in each case. In a solution used to block chemical synaptic connections, depolarization or hyperpolarization $( \pm 10$ $\mathrm{nA}$, arrowheads) of B51 depolarized or hyperpolarized B64, respectively (B3; B51 was continuously hyperpolarized to prevent the induction of its plateau potential).

the action potentials in B51 (Fig. 4A1). They were not abolished when the preparations $(n=3)$ were bathed in a high divalent solution (Fig. 4A2); the membrane potential of B8 was not changed by hyperpolarizing current pulses in B51; and the EPSPs were suppressed in a solution in which $\mathrm{Ca}^{2+}$ was replaced by $\mathrm{Co}^{2+}$. This result does not exclude the possibility that in addition to this apparent chemical monosynaptic connection, B51 may excite the ipsilateral B8 through polysynaptic pathways. B51 did not appear to synapse with the contralateral B8 (data not shown).

We also tested for synaptic connections between B51 and the ipsilateral retraction generator neuron B64. In normal saline, depolarization of B51 by a brief current pulse drives a plateau potential in B51 that outlasts the current pulse. This depolarization also can drive a high-frequency burst of action potential in a previously silent B64. This excitation was associated with EPSPs in B64 having a constant delay and a one-for-one relationship with the spikes in B51 (Fig. 4B1). These EPSPs can be reduced, but not suppressed, by bathing the preparation in a solution in which $\mathrm{Ca}^{2+}$ has been replaced by $\mathrm{Co}^{2+}$ (Fig. 4B2). In addition, in such a solution depolarizing and hyperpolarizing current pulses in B51 were still able to depolarize and hyperpolarize B64 (Fig. 4B3). Thus, B51 appeared to excite the ipsilateral B64 by both excitatory chemical and electrical connections. Only an electrical connection was found between B51 and the contralateral B64. These results suggest that B51 mediates features of pattern $\mathrm{I}$, at least in part, by synaptic connections to the closure motor neurons B8 and the retraction generator neuron B64. They do not exclude the possibility, however, that other monosynaptic or polysynaptic pathways contribute to the control of the features of pattern I by activity of B51.

Activity in B51 was a key determinant for the expression of pattern I (Fig. 3A) (see also Nargeot et al., 1999a). Thus, activity in B51 could be implicated in selective modifications of pattern I by contingent reinforcement. In previous studies (Nargeot et al., 1997b, 1999a,b; Baxter et al., 1998) we found that the occurrences of pattern I induced by stimulation of n.2,3 were selectively enhanced by contingent stimulation of $\mathrm{E} n$.2. In this analog of operant conditioning, the enhancement of pattern I was associated with an enhancement of activity in the closure motor neurons B8 (Nargeot et al., 1997b) and with changes in the membrane properties of B51 (Nargeot et al., 1999a). Thus, we tested whether the selective modification of pattern I (and thus of closure activity during the retraction phase) could result from the modification of activity in B51.

\section{Conditioned changes in B51 membrane properties}

B51 was primarily active during pattern I. Thus, the contingent association of reinforcement (i.e., stimulation of $\mathrm{E}$ n.2) with pattern I was accompanied by a contingent association of reinforcement with activity in B51. To examine the role of B51 in the contingent-dependent enhancement of pattern I, we tested whether explicit association of reinforcement with activity of B51 in the absence of stimulation of the peripheral nerve n.2,3 could modify the cellular properties and activity in B51 and could contribute to the enhancement of pattern I.

We used three groups of nine preparations (i.e., contingent reinforcement, yoke control, control). In the three groups, the experiments were composed of a pretraining period, a $10 \mathrm{~min}$ training period, and a test period. The paradigms differed from those used previously (Nargeot et al., 1997b, 1999a,b) by the absence of stimulation of n.2,3 during the training period, so that no rhythmic activity was induced during this period. In all groups, brief $(5 \mathrm{sec})$ intracellular current injection was used to activate B51. The intensity of the pulses was adjusted to $2 \mathrm{nA}$ above the threshold that elicited the plateau properties in B51 during the pretraining period (see below). Because an average of seven occurrences of pattern I was observed in the 10 min training period of previous experiments (Nargeot et al., 1997b), seven depolarizing current pulses were delivered in the present study. A random number generator determined the intervals between the pulses. In the contingent-reinforcement group, a phasic $(10 \mathrm{~Hz}, 6$ sec) electrical stimulation of $\mathrm{E} \mathrm{n} .2$ was made contingent on activity of B51 (Fig. 5A). Thus, the stimulation immediately followed the current pulse or the elicited bursting activity in B51. In the yoke-control group, each preparation received the stimulation of E n.2 with the same parameters and timing as in a paired 


\section{A. Contingent Reinforcement}

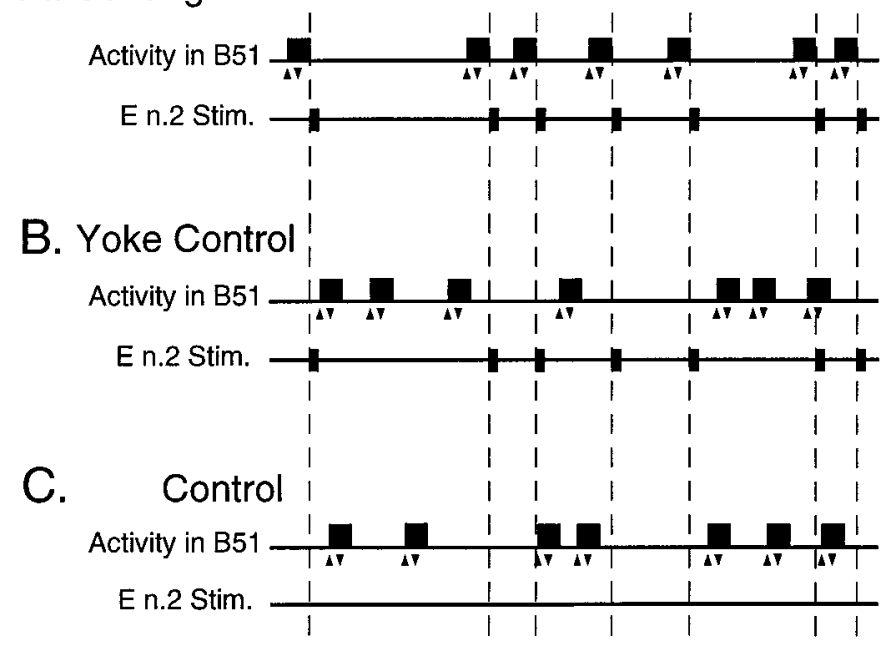

Figure 5. Training protocol for contingent reinforcement of activity in B51. Three groups of preparations were used: contingent reinforcement, yoke control, and control. In all groups, B51 was depolarized by seven current pulses $(5 \mathrm{sec}$ with an intensity adjusted $2 \mathrm{nA}$ above the threshold that elicits bursting activity in B51; arrowheads indicate the onset and offset of the current) that were randomly distributed throughout the 10 min training period. The responses of B51 to the depolarizations are illustrated by the black squares. In the contingent-reinforcement preparation $(A)$, phasic $(6 \mathrm{sec}, 10 \mathrm{~Hz})$ stimulation of $\mathrm{E} \mathrm{n} .2$ (black rectangles in $\mathrm{E}$ n.2) was delivered immediately after the induced activity in B51. In the yoke-control preparation $(B)$, stimulation of $\mathrm{E}$ n.2 (black rectangles in $\mathrm{E}$ n.2) was applied with the same parameters and timing as that in a matched contingent-reinforcement preparation (dashed lines). Thus, stimulation of $\mathrm{E} \mathrm{n.2}$ was not contingent with the activity in B51 in the yoke-control preparation but was "yoked" to the stimulation of E n.2 in the previous contingent-reinforcement preparation. In the control preparation $(C), \mathrm{E}$ n.2 was not stimulated. Note that the peripheral nerve 2,3 was not stimulated in any of the protocols.

contingent-reinforcement preparation (Fig. 5B). However, the timing of depolarization in B51 used in the yoke-control preparation was generated by a different random number series than in the contingent-reinforcement preparation. Thus, in the yokecontrol group, there was no association of stimulation of $\mathrm{E}$ n.2 with depolarization of B51. Finally, in the control group, the depolarization of B51 was also generated randomly, but no stimulation of E n.2 was used (Fig. 5C).

The effects of the experimental paradigms on the neuronal activity were tested during the test period that was composed of two successive phases. During the first test phase beginning immediately after the training period, we examined the input resistance of B51 and the threshold to elicit a plateau potential in B51. No stimulation of n.2,3 was used. The second test phase began immediately after the first. The starting time of this phase varied from one preparation to another but never started later than $1 \mathrm{hr}$ after the training period and was statistically undistinguishable between the three groups of preparations $(H=0.309$; $\mathrm{df}=2$; contingent reinforcement, $14.9 \pm 1.6 \mathrm{~min}$; yoke control, $17.4 \pm 3.2 \mathrm{~min}$; control, $17.6 \pm 2.4 \mathrm{~min})$. During this second test phase, monotonic $(4 \mathrm{~Hz})$ stimulation of $\mathrm{n} .2,3$ was delivered for 20 min, and the induced rhythmic motor patterns were compared between groups during the last $10 \mathrm{~min}$ of stimulation.

Using this experimental paradigm, we first examined whether the association of stimulation of E n.2 with depolarization of B51 modified the membrane properties of this cell. Brief $(5 \mathrm{sec})$ hyperpolarizing $(-5 \mathrm{nA})$ current pulses were used to determine the input resistance of B51 before training and during the first test phase. In the contingent-reinforcement preparation, the input resistance was increased after training as compared with before training (Fig. 6A1). An enhancement of the input resistance was not observed in the control or the yoke-control preparations. Comparisons of the changes in input resistance (i.e., the difference between the post-training and the pretraining values relative to the pretraining value) indicated a significant difference among groups (Fig. 6A2) $(H=10.282$; df $=2 ; p<0.01)$. The modifications were significantly larger in the contingentreinforcement group as compared with either the yoke-control $\left(q_{2}\right.$ $=4.496 ; p<0.005)$ or the control group $\left(q_{3}=4.410 ; p<0.01\right)$. There was no significant difference in the input resistance of B51 between the yoke-control and control groups $\left(q_{2}=0.797\right)$.

These data indicated that the input resistance of B51 was modified by the contingent stimulation of E n.2 on activity of B51. This effect was induced by the stimulation of E n.2 and depended on the contingency of this stimulation with the depolarization in B51 because it was not induced in either the yoke-control or control groups.

Moreover, in some of these preparations (i.e., seven of nine in each group), we tested whether these modifications in the membrane resistance in B51 were associated with changes in the excitability of B51. B51 has regenerative properties that allow the cell to respond to a brief $(5 \mathrm{sec})$ depolarizing current pulse with a burst of activity at a high frequency that outlasted the current pulse. We defined the threshold for eliciting bursting activity in B51 as the minimum amount of current necessary to drive this activity in each of two successive pulses of the same intensity. The capability to elicit a burst of spikes in B51 was generally all or none. Thus, current pulses of progressively increasing intensity were either unable to produce activity or elicited a strong bursting activity that outlasted the current pulse (Plummer and Kirk, 1990; Nargeot et al., 1999).

In the contingent-reinforcement preparations, less current injection was necessary to drive the plateau potential and bursting activity in B51 after training than before training (Fig. 6B1). In contrast, in the yoke-control and control preparations, the same amount of current drove the bursting activity in B51 before and after training. A comparison of the changes in the burst threshold (difference between the post-training and the pretraining values normalized to the pretraining value) indicated a significant difference among groups (Fig. 6B2) $(H=8.314$; df $=2$; $p<0.02)$. The modifications in the burst threshold were significantly different in the contingent-reinforcement group as compared with either the yoke-control $\left(q_{3}=3.533 ; p<0.05\right)$ or control group $\left(q_{2}\right.$ $=4.924 ; p<0.001)$. No significant difference was observed between the yoke-control and the control groups $\left(q_{2}=0.316\right)$. Thus, the threshold of bursting activity in B51 was decreased specifically as a result of the contingent stimulation of $\mathrm{E} \mathrm{n.2}$ on depolarization in B51.

These results indicated that contingent stimulation of E n.2 on depolarization in B51 modified the regenerative properties of B51 and thereby increased the excitability in this cell. These modifications were similar to those induced by a neuronal analog of operant conditioning in which stimulation of E n. 2 was contingent on the occurrences of pattern I [see accompanying article (Nargeot et al., 1999a)]. In this previous study, monotonic stimulation of n.2,3 was used during the training period to induce rhythmic motor activity. In the present training procedure, no stimulation of n.2,3 was used. Thus, the similarity of the modifications in the membrane properties of B51 in the contingent- 


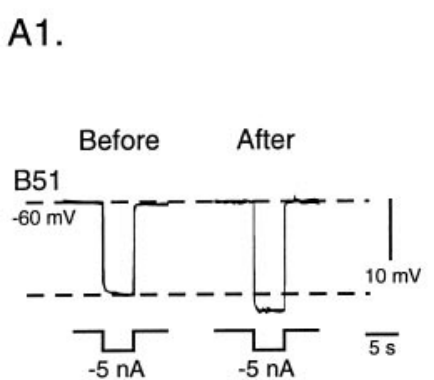

B1.

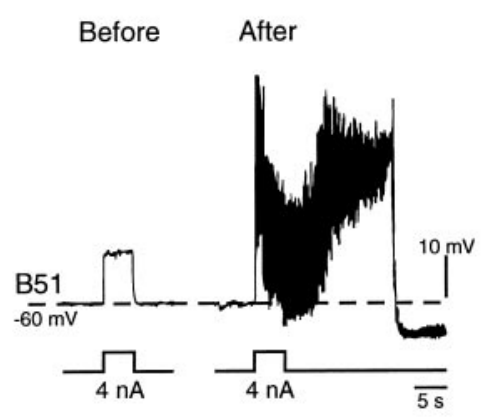

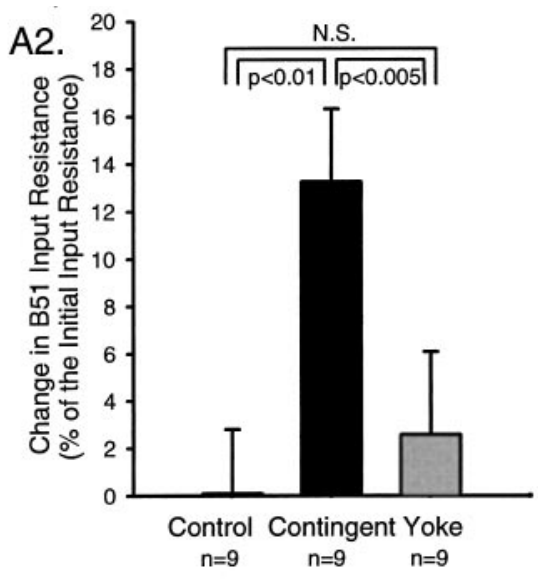

B2.

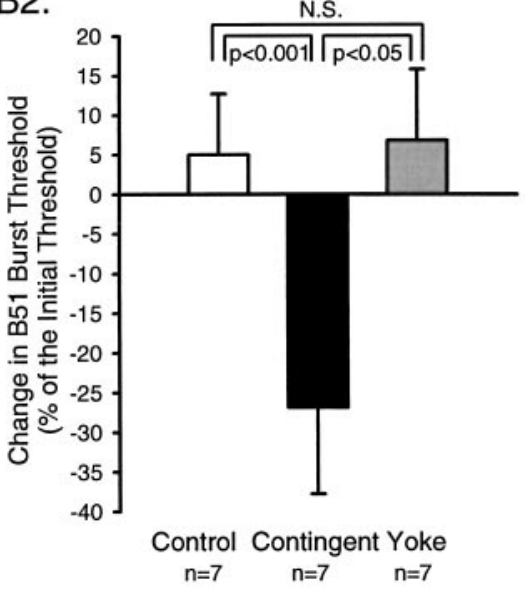

Figure 6. Induced changes in B51 membrane properties. $A 1$, Input resistance of B51 tested by a brief current pulse (5 sec, $-5 \mathrm{nA}$ ) was increased After a contingent-reinforcement paradigm as compared with Before (bottom dashed line). B51 was held at $-60 \mathrm{mV}$ (top dashed line). A2, Change in input resistance of B51 normalized to the pretraining value was significantly higher in the contingent-reinforcement group (black bar) than either in the control (white bar) or in the yoke-control group (gray bar). No significant change (N.S.) was observed between yoke-control and control groups. B1, Threshold for bursting activity in B51, tested by a brief current pulse ( $5 \mathrm{sec}, 4 \mathrm{nA}$ ) was decreased After a contingentreinforcement paradigm as compared with Before. B51 was held at $-60 \mathrm{mV}$ (dashed line). B2, Changes of threshold for bursting activity in B51 significantly decreased in the contingent-reinforcement group (black bar) as compared with either the control (white bar) or yoke-control group ( gray bar). No significant change (N.S.) was observed between yoke-control and control groups. reinforcement groups indicates that the induction of the contingent-dependent modifications of B51 does not require the stimulation of n.2,3.

Previously, we found that activity in B51 was associated with the expression of pattern I. Thus, we examined whether the contingent-dependent modification in the membrane properties in B51 also selectively enhanced the expressions of pattern I.

\section{Selective modification of motor patterns}

To determine whether the contingent-dependent modifications of B51 properties modified the functioning of the buccal circuitry, we compared activity in B51 and the motor patterns induced by stimulation of n.2,3 in the preparations from each of the three groups of preparations described above (i.e., Fig. 5; contingent reinforcement, yoke control, control). This paradigm was applied in eight of the nine preparations used in each group.

Figure $7 A-C$ illustrates the dynamics of activity in B51 in a control preparation (Fig. $7 A$ ), a contingent-reinforcement preparation (Fig. $7 B$ ), and a yoke-control preparation (Fig. $7 C$ ). These activities in B51, induced by stimulation of n.2,3, resulted from variable switching between inactive (i.e., the cell was depolarized but did not produce an activity) and active states (Fig. 1). In our companion paper (Nargeot et al., 1999a), we found that the bursts of action potentials in B51 (i.e., activity with a frequency higher than $4 \mathrm{~Hz}$ for $>1 \mathrm{sec}$; Fig. 7, black triangles) were primarily correlated with the occurrences of pattern I rather than with other patterns. In the present study, we found that the frequency of occurrences of such pattern I-related activity in B51 was significantly different among groups (Fig. 8$)(H=7.451$; df $=2$; $p<0.025)$. These occurrences were significantly higher in the contingent-reinforcement preparations than in the control $\left(q_{2}=\right.$ $4.270 ; p<0.005)$ or the yoke-control $\left(q_{3}=3.650 ; p<0.05\right)$ preparations. No significant difference was observed between the control and the yoke-control $\left(q_{2}=1.151\right)$ groups.

Thus, the contingent-reinforcement protocol that modified the membrane properties of B51 and increased the excitability of this cell also modified the dynamics of activity in B51 during rhythmic motor patterns. Because the afferent nerve (n.2,3) was not stimulated during training, there was no contingent relationship between activity in n.2,3 and reinforcement. Thus, the contingentdependent modifications of the dynamics of B51 were probably not related to changes in the afferent pathway but rather were probably mediated by the contingent-dependent modifications of the intrinsic properties of B51. This contingent-dependent modification of the functional dynamics of B51 resulted from a selective enhancement of the occurrences of pattern I-related activity. Thus, we expected that such an enhancement might be associated with a selective enhancement of the occurrences of pattern I.

In the same groups of preparations, we compared the occurrences of the different motor patterns induced by the monotonic stimulation of n.2,3. Typical recordings of the motor patterns in a control preparation, a contingent-reinforcement preparation, and a yoke-control preparation are illustrated in Figure 9. These 

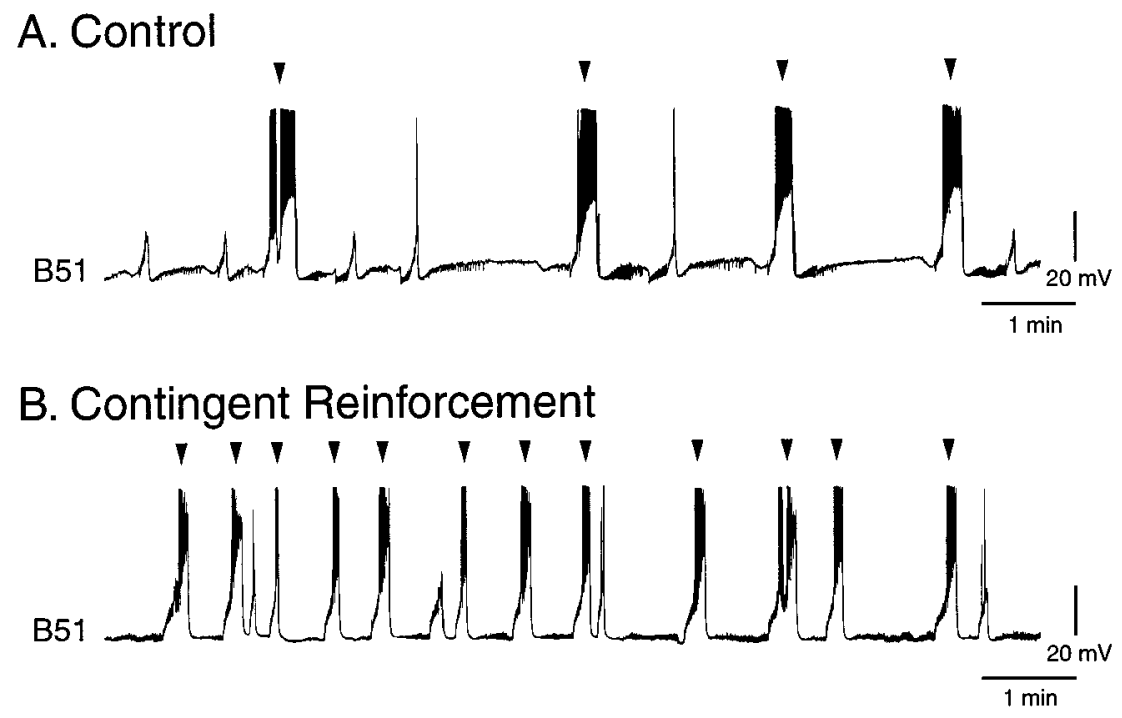

\section{Yoke Control}

Figure 7. Increased occurrences of bursting activity in B51. The number of occurrences of bursting activity in B51 (i.e., activity longer than $1 \mathrm{sec}$ and higher than 4 $\mathrm{Hz}$; black triangles) induced by monotonic stimulation of n.2,3 during a 10 min test phase after training increased in a contingent-reinforcement preparation $(B)$ as compared with a control preparation $(A)$ and a yoke-control preparation $(C)$.

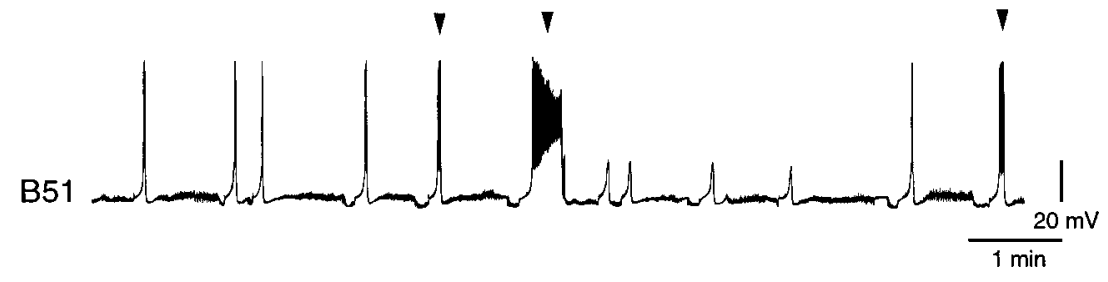

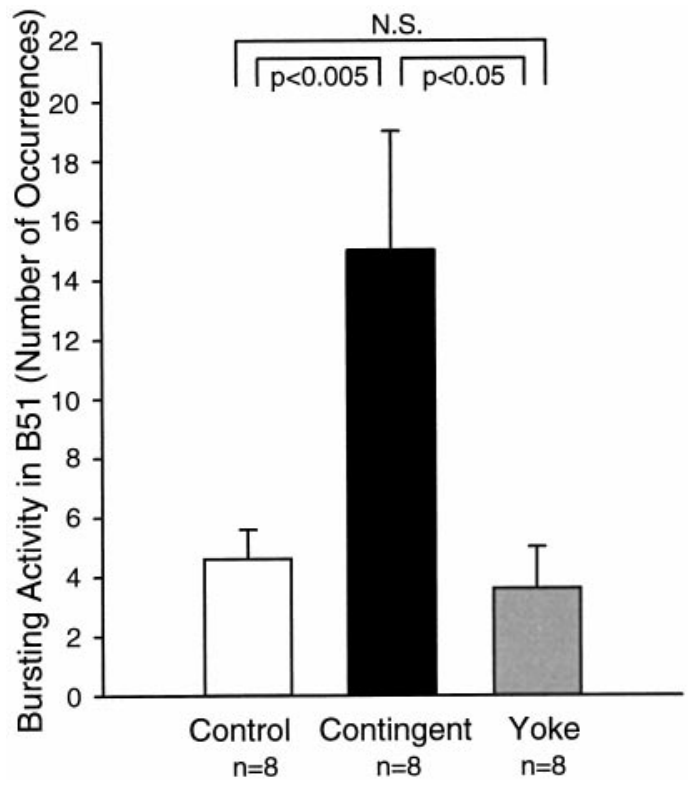

Figure 8. Comparison of occurrences of bursting activity in B51. The occurrences of bursting activity in B51 during a 10 min test phase were significantly increased in the contingent-reinforcement group (black bar) as compared with either the control (white bar) or yoke-control group (gray bar). No significant difference (N.S.) was observed between the control and the yoke-control groups.

recordings illustrate that the occurrences of pattern I were increased in the contingent-reinforcement preparation as compared with either the control or the yoke-control preparations. These occurrences were similar between the control and the yokecontrol preparations. Moreover, the occurrences of the other motor patterns (i.e., pattern II and intermediate patterns) were comparable among preparations.

These observations were supported by statistical comparison of the occurrences of the motor patterns in the three groups of preparations (Fig. 10). The number of occurrences of pattern I was significantly different among groups (Fig. 10A) $(H=10.882$; $\mathrm{df}=2 ; p<0.005)$. It was significantly higher in the contingentreinforcement group as compared with either the control $\left(q_{2}=\right.$ $4.419 ; p<0.01)$ or yoke-control group $\left(q_{3}=4.450 ; p<0.005\right)$. No significant difference was observed for the number of occurrences of pattern I between the control and the yoke-control groups $\left(q_{2}\right.$ $=2.191)$. This enhancement of motor patterns was selective to occurrences of pattern I. In the same preparations and during the same test phase, no significant difference was observed in the occurrences of the other patterns (i.e., pattern II and intermediate patterns) (Fig. $10 B)(H=0.752 ; \mathrm{df}=2)$ or incomplete patterns $(H=0.834$; df $=2$; contingent reinforcement, $1.4 \pm 1.0$; yoke control, $0.9 \pm 0.9$; control, $1.2 \pm 1.1$ ).

These results indicate that contingent stimulation of E n.2 on activity in B51 could be responsible for the enhancement of pattern I. These modifications could not result from changes in the peripheral pathway n.2,3, which was not stimulated during training, but rather, this selective and contingent-dependent modification of pattern I could be mediated by the regulation of the dynamical properties of B51.

\section{DISCUSSION}

Role for afferent stimulation in operant conditioning

In some operant conditioning paradigms, sensory stimuli have been explicitly used to set the occasions on which a particular motor output and delivery of reinforcement were associated (Thorndike, 1933; Skinner, 1938; Rescorla, 1987; Wolpaw, 1987; 


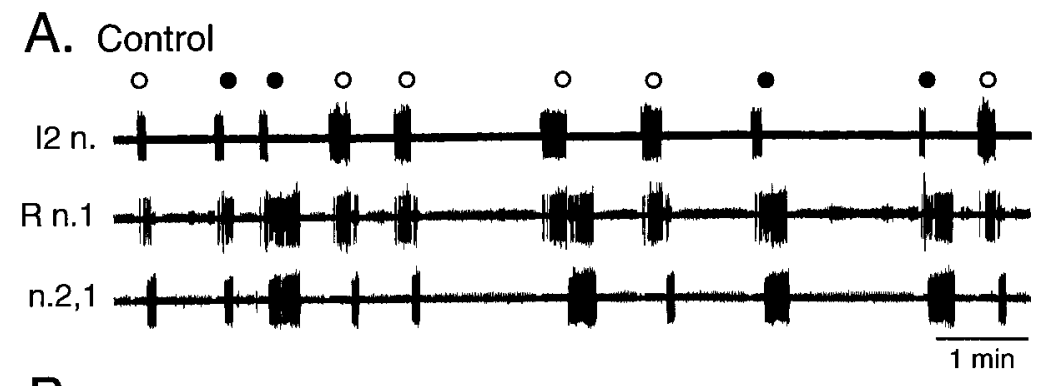

B. Contingent Reinforcement

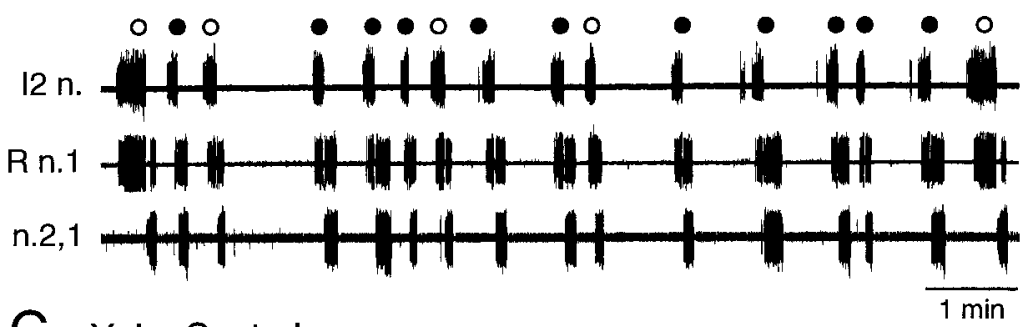

C. Yoke Control

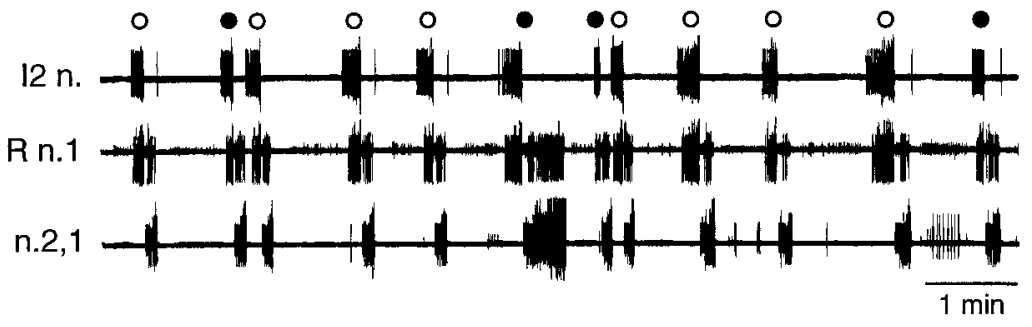

Figure 9. Enhancement of the probability of occurrence of pattern I. Rhythmic motor patterns (pattern I, $\mathbf{0}$; and other patterns, $\bigcirc$ ) induced by monotonic stimulation of n.2,3 were recorded in $\mathrm{I} 2 \mathrm{n}$. (i.e., protraction phase), in $\mathrm{R}$ n.1 (i.e., closure activity), and in n.2,1 (i.e., retraction phase) in a control $(A)$, a contingent-reinforcement $(B)$, and a yoke-control preparation $(C)$ during a 10 min test phase after training. The probabilistic occurrence of pattern I was increased in a contingentreinforcement preparation as compared with a control and a yoke-control preparation.
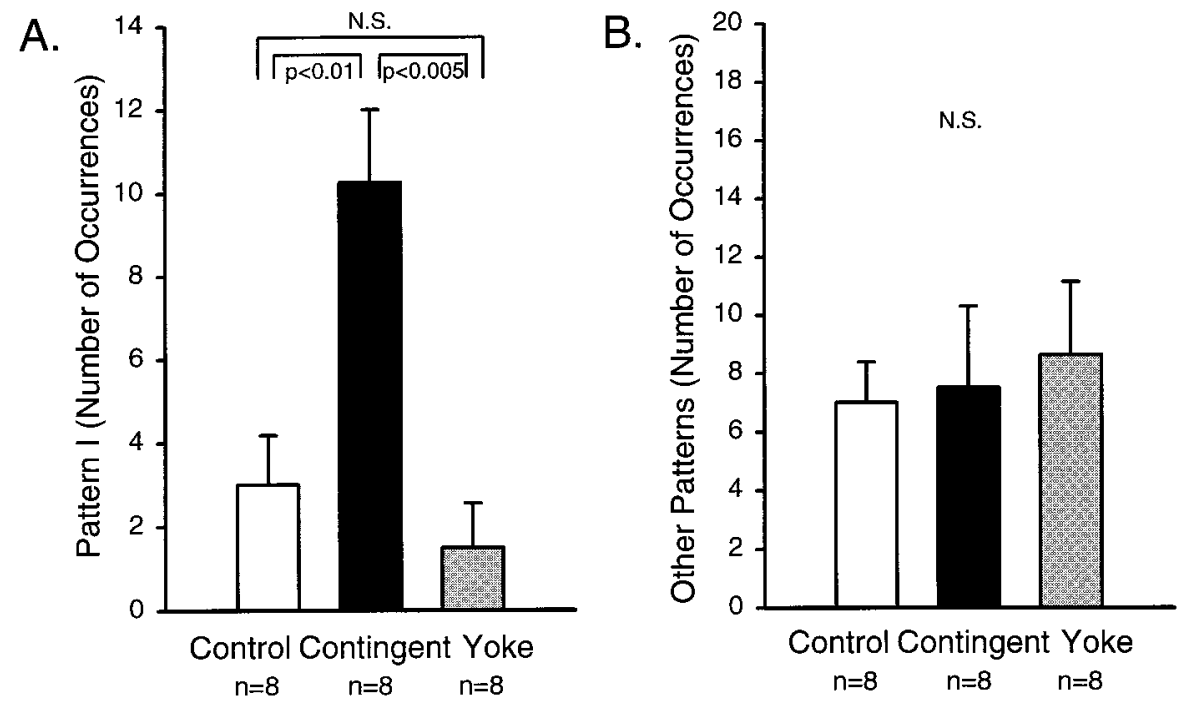

Figure 10. Selective enhancement of occurrence
of pattern I. A, A comparison of the number of
occurrences of pattern I during a 10 min test phase
in a control (white bar), a contingent-
reinforcement (black bar), and a yoke-control
group ( gray bar) indicated a significant enhance-
ment of the occurrence of this pattern in the
contingent-reinforcement group as compared with
either control or yoke-control group. No signifi-
cant (N.S.) change was observed between the con-
trol and the yoke-control groups. B, In the same
preparations as in $A$ and during the same test
phase, no significant (N.S.) change in the number
of occurrences of the other patterns (i.e., pattern
II and intermediate patterns) was observed among
the different groups.

Colwill and Rescorla, 1990). It is unclear whether these sensory stimuli are necessary for learning or whether they simply contribute to the occurrence of behaviors without being required for the learning. One of the goals of the present study was to investigate the role of sensory stimuli in an operant conditioning paradigm.

In the analog of operant conditioning in the isolated buccal ganglia in Aplysia, different motor patterns (e.g., pattern I and pattern II) similar to those observed during consummatory feeding behaviors were induced by monotonic stimulation of the peripheral nerve n.2,3. This pathway conveyed, at least in part, sensory input (Nargeot et al., 1995, 1997b). Several lines of evidence suggested that stimulation of n.2,3 was not essential to the induction of the contingent-dependent modifications of the buccal motor output. First, in previous studies (Nargeot et al., 1997b, 1999a), identical paradigms for stimulation of n.2,3 and reinforcement were used in the contingent-reinforcement and yoke-control groups, but only the contingent-reinforcement group expressed enhancement of occurrences of pattern I and of excitability in B51. Thus, simply pairing stimulation of n.2,3 with reinforcement cannot account for the modifications. Second, in the present study, we induced the enhanced occurrences of pattern I and of excitability in B51 by a training procedure in which 
n.2,3 was not stimulated. Thus, reinforcement can induce the neuronal modifications without stimulation of n.2,3. Although these results do not exclude the possibility that the pathway n.2,3 may be a locus of neuronal modification, they indicate that this stimulation is not necessary to induce the contingent-dependent modifications of the neuronal activity.

Moreover, stimulation of n.2,3 activated central neuronal networks that themselves generated and determined the probabilistic occurrences of different motor outputs. Thus, by its actions on the central network, this peripheral stimulation does not elicit a specific motor pattern with a predictable relationship. Rather, it sets the occasions on which a particular motor output and delivery of reinforcement were associated.

These results do not support the hypothesis that sensory stimuli are essential in operant conditioning and that the neuronal modifications result from a stimulus-response association (Guthrie, 1935). Rather, the data are more consistent with the hypothesis that emitted behaviors are modified via an association between functional dynamics of central neuronal units mediating behavior and the reinforcement (Tolman, 1949; Rescorla, 1987).

\section{A neuronal substrate of selective modification in operant conditioning}

Different behaviors involving both common and distinct motor acts can be expressed in a given environmental situation. In operant conditioning, the occurrence of a designated behavior that has been associated with reinforcement is selectively modified in regard to the other behaviors. This empirical selective modification is a consequence of the contingent association that characterizes operant conditioning and indicates that a particular behavior can be selected from among others by the environmental contingencies (Thorndike, 1933; Skinner, 1981). A selective modification of a designated motor output by contingent reinforcement was previously demonstrated in the isolated buccal ganglia and provides an opportunity to investigate the neuronal basis of selective modification (Nargeot et al., 1997b, 1999a,b).

The central neuronal network that generates the different buccal motor patterns is composed of two broad classes of neurons: those that generate features common to all motor patterns (e.g., protraction and retraction) and those that generate the distinguishing features of specific patterns (e.g., ingestion, egestion) (Fig. 11). Neurons that produce features common to all motor patterns, such as B31/32 and B64 (i.e., protraction and retraction generators) (Susswein and Byrne, 1988; Hurwitz and Susswein, 1996), are essential in pattern genesis because suppression of their firing impaired expression of motor patterns. In contrast, neurons such as B51 and B34 (Plummer and Kirk, 1990; Hurwitz et al., 1997; Nargeot et al., 1999a) are not active in all motor patterns, and the occurrence of their activity can change in an unpredictable manner from one pattern to another. Experimental manipulations of such "incidental activity" do not induce or suppress motor patterns but initiate or suppress the distinguishing features of specific patterns.

Activity in B51 is not essential for the genesis of common features of the patterns. Motor patterns occur even when B51 is silent, but the incidental occurrence of activity in B51 with motor patterns contributed to distinguishing features of pattern I (i.e., occurrence of activity in the closure motor neurons B8 during a prolonged retraction phase of the pattern). This effect of B51 is exerted through diverse synaptic connections such as those to the B8 closure motor neurons and the B64 retraction generator (Fig. 11). The coefficient of determination (Nargeot et al., 1999a)
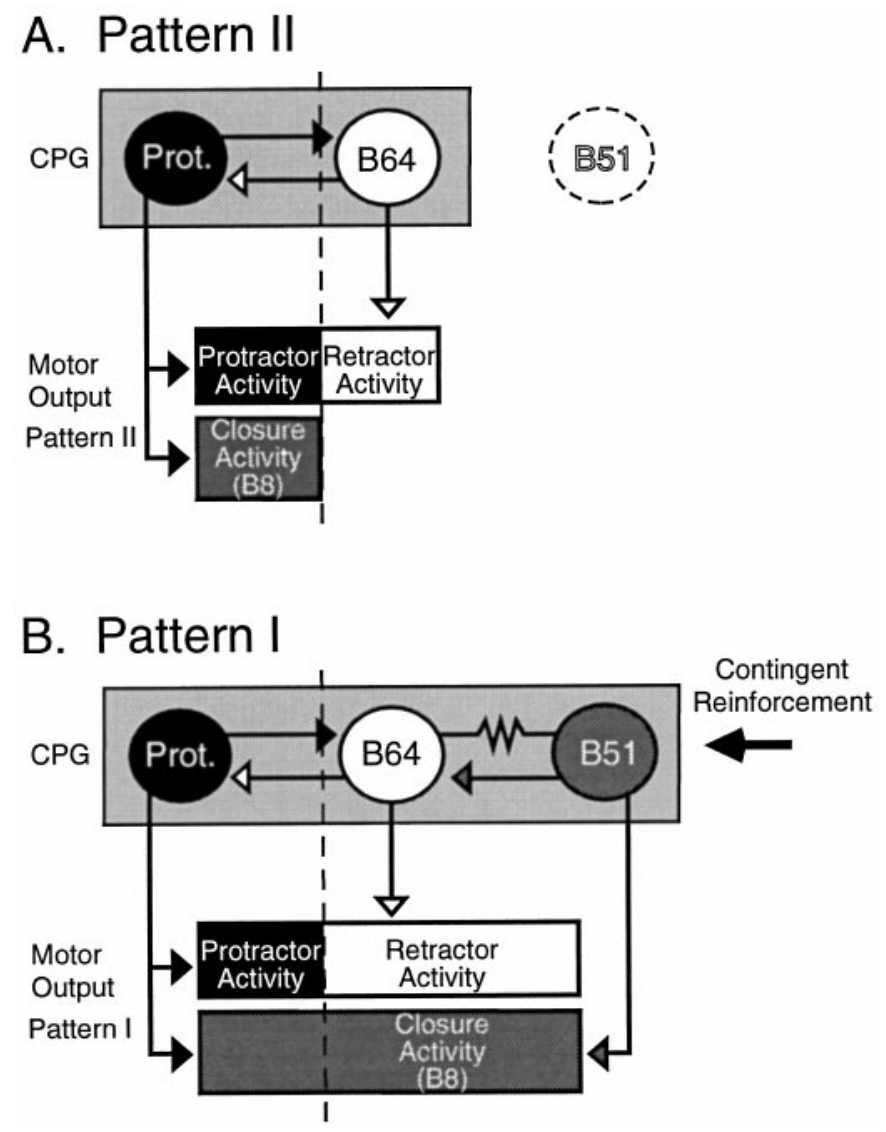

Figure 11. Model of contingent-dependent enhancement of pattern I. The buccal motor patterns (Pattern II, A; Pattern I, B) are basically composed of protractor motor activity (black rectangle) elicited by a protraction generator (Prot.) and retractor motor activity (white rectangle) elicited by a retraction generator (B64). The generators are synaptically interconnected (arrows). Neurons from the protraction generator activate the closure motor activity during the protraction phase (i.e., B8; dark gray rectangle). Dashed lines indicated the transition between events occurring during the protraction (left) and retraction (right) phases. In Pattern II $(A)$, the closure motor activity occurs in phase with the protractor motor activity. B51 is not active (dashed circle). Pattern $I(B)$ is distinguished by closure activity that occurs during an extended retraction phase. In addition, B51 is one of possibly several cells that are recruited into the CPG during the retraction phase. Recruitment of activity in B51 and other pattern I-specific cells (not illustrated) activate different neurons (e.g., B8, B64; identified chemical and electrical synapses are represented by arrows and resistance symbol, respectively) that together allow the expression of the distinguishing features of pattern I. Contingent reinforcement (bold arrow) of probabilistic occurrence of pattern I, or activity in B51, induced functional changes in B51 (and perhaps other neurons) that result in an enhancement of bursting activity in cell B51. The enhanced recruitment of activity of B51 in the CPG is associated with an increased occurrence of pattern I.

suggests that bursting activity in B51 can predict $\sim 70 \%$ of the distinguishing features of pattern I during the retraction phase.

Contingent reinforcement of a specific motor pattern produces a tight association between reinforcement and the incidental activities that characterize the reinforced pattern. We found that such an explicit association between reinforcement and activity in B51 induced neuronal processes that were important to the selective enhancement of pattern I. These data do not indicate that B51 was sufficient by itself either to induce or express the neuronal plasticity mediating the selection of pattern I. B51 activates other neurons (e.g., B8, B64) that may also participate in the 
induction or expression of the neuronal modifications. These data suggest, however, that incidental activities generated by cells or network properties and their modifications by contingent reinforcement may constitute part of the neuronal substrate that underlies the selective modification in operant conditioning.

\section{Cellular modifications in operant conditioning}

The present data demonstrated the importance of the association between reinforcement and centrally emitted neuronal activities to induce the neuronal plasticity that underlies features of operant conditioning. Although our data cannot exclude a role for the peripheral stimulation, this stimulation was not essential to inducing the neuronal modifications that underlie the characteristic features of operant conditioning. Rather, the dynamical properties of networks or neurons can provide the substrate of the association between specific neuronal activity and reinforcement. Thus, dynamic properties of neuronal circuits and cells could be an essential factor for induction of neuronal plasticity underlying operant conditioning (Woollacott and Hoyle, 1977; Stein and Belluzzi, 1989).

Three forms of plasticity in B51 were associated with the selective enhancement of a designated motor pattern (i.e., pattern I) by reinforcement. They were changes in input resistance, in threshold for generating plateau potential, and in occurrence of bursting activity. These modifications, which were induced in the absence of stimulation of n.2,3, were similar to those induced in the presence of this stimulation (Nargeot et al., 1999a). Our data did not investigate a causal relationship among changes in input resistance, threshold of plateau potential, and enhancement of pattern I, or a possible mechanistic link between these three forms of plasticity. Rather, we investigated the relationship between the enhancement of occurrences of the bursting activity in B51 and an enhancement of pattern I. Stimulation of E n.2 that was contingent on bursting activity in B51 increased the occurrences of both bursting in B51 and the expression of pattern I during subsequent monotonic stimulation of n.2,3. This result suggests that modifying the dynamical properties of B51 plays a key role in this analog of operant conditioning.

Dynamical properties such as regenerative membrane conductances that underlie plateau potentials and bursting activity have been characterized in various neurons and may underlie functional dynamics of cells and neuronal networks (Russell and Hartline, 1978; Connors et al., 1982; Fricke and Prince, 1984; Llinas, 1988; Kiehn, 1991; Steriade et al., 1993; Bianchi et al., 1995; Marder and Calabresse, 1996; Russo and Hounsgaard, 1996). Modulation of such dynamical properties could be an essential factor for induction of operant conditioning. Persistent modifications of regenerative properties may be induced by different types of input (i.e., sensory, modulatory) (Dickinson and Nagy, 1983; Llinas and Yarom, 1986; Turrigiano et al., 1994; Lechner et al., 1996; Marder et al., 1996; Canavier et al., 1997) (also see McCormick, 1989; Harris-Warrick and Marder, 1991; Hultborn and Kiehn, 1992). Our data extend these observations by demonstrating that changes in the dynamical properties of neurons can depend on a tight association between occurrences of cellular activity and a presynaptic input. Several examples of activity-dependent modulation of neuronal properties have been described previously (Hawkins et al., 1983; Walters and Byrne, 1983; Nowak et al., 1984; Kelso et al., 1986; Crow and Forrester, 1991). Similar processes may be implicated in the modifications of the bursting properties of neurons (Kramer and Levitan, 1990).

Recently, studies in the isolated buccal ganglia have found that the reinforcing pathway produced apparent monosynaptic input on B51 and have identified dopamine as a putative neurotransmitter (Susswein et al., 1993; Baxter et al., 1998; Kabotyanski et al., 1998; Nargeot et al., 1999b). Future studies will investigate whether this input mediates the contingent-dependent modifications of the dynamical properties of B51 and whether the underlying cellular mechanisms can be related to those suggested for other examples of associative learning (Hawkins et al., 1983; Walters and Byrne, 1983, 1985; Ocorr et al., 1985; Raymond et al., 1992; Murphy and Glanzman, 1997; Bao et al., 1998) (also see Abrams and Kandel, 1988; Lechner and Byrne, 1998).

\section{REFERENCES}

Abrams TW, Kandel ER (1988) Is contiguity detection in classical conditioning a system or a cellular property? Learning in Aplysia suggests a possible molecular site. Trends Neurosci 11:128-136.

Bao J-X, Kandel ER, Hawkins RD (1998) Involvement of presynaptic and postsynaptic mechanisms in a cellular analog of classical conditioning at Aplysia sensory-motor neuron synapses in isolated cell culture. J Neurosci 18:458-466

Baxter DA, Nargeot R, Patterson GW, Byrne JH (1998) A dopamine antagonist (ergonovine) impaired the enhancement of motor patterns by contingent reinforcement in the isolated buccal ganglia of Aplysia. Soc Neurosci Abstr 24:1891.

Bianchi AL, Denavit-Saubié M, Champagnat J (1995) Central control of breathing in mammals: neuronal circuitry, membrane properties, and neurotransmitters. Physiol Rev 75:1-45.

Bolles RC (1972) Reinforcement, expectancy, and learning. Psychol Rev 79:394-409.

Byrne JH, Castellucci VF, Kandel ER (1978) Contribution of individual mechanoreceptor sensory neurons to defensive gill-withdrawal reflex in Aplysia. J Neurophysiol 41:418-431.

Canavier CC, Butera RJ, Dror RO, Baxter DA, Clark JW, Byrne JH (1997) Phase response characteristics of model neurons determine which patterns are expressed in a ring circuit model of gait generation. Biol Cybern 77:367-380.

Colwill RM, Rescorla RA (1990) Evidence for the hierarchical structure of instrumental learning. Anim Learn Behav 18:71-82.

Connors BW, Gutnick MJ, Prince DA (1982) Electrophysiological properties of neocortical neurons in vitro. J Neurophysiol 48:1302-1320.

Crow T, Forrester J (1991) Light paired with serotonin in vivo produces both short- and long-term enhancement of generator potentials of identified B-photoreceptors in Hermissenda. J Neurosci 11:608-617.

Dickinson PS, Nagy F (1983) Control of a central pattern generator by an identified modulatory interneurone in crustacea. II. Induction and suppression of plateau properties in pyloric neurones. $J$ Exp Biol 105:59-82.

Fetz EE, Finocchio DV (1971) Operant conditioning of specific patterns of neural and muscular activity. Science 174:431-435.

Fox SS, Rudell AP (1968) Operant controlled neural event: formal and systematic approach to electrical coding of behavior in brain. Science 162:1299-1302.

Fox SS, Rudell AP (1970) Operant controlled neural event: functional independence in behavioral coding by early and late components of visual cortical evoked response in cats. J Neurophysiol 33:548-561.

Fricke RA, Prince DA (1984) Electrophysiology of the dentate gyrus granule cells. J Neurophysiol 51:195-209.

Guthrie ER (1935) The psychology of learning. New York: Harper.

Harris-Warrick RM, Marder E (1991) Modulation of neural networks for behavior. Annu Rev Neurosci 14:39-57.

Hawkins RD, Abrams TW, Carew TJ, Kandel ER (1983) A cellular mechanism of classical conditioning in Aplysia: activity-dependent amplification of presynaptic facilitation. Science 219:400-405.

Hull CL (1943) Principles of behavior. New York: Appleton-CenturyCrofts.

Hultborn H, Kiehn O (1992) Neuromodulation of vertebrate motor neuron membrane properties. Curr Opin Neurobiol 2:770-775.

Hurwitz I, Susswein AJ (1996) B64, a newly-identified central pattern generator element producing a phase switch from protraction to retraction in buccal motor programs of Aplysia californica. J Neurophysiol 75:1327-1344.

Hurwitz I, Kupfermann I, Susswein AJ (1997) Different roles of neurons 
B63 and B34 that are active during the protraction phase of the buccal motor programs in Aplysia californica. J Neurophysiol 78:1305-1319.

Kabotyanski EA, Baxter DA, Byrne JH (1998) Identification and characterization of catecholaminergic neuron B65, which initiates and modifies patterned activity in the buccal ganglia of Aplysia. J Neurophysiol 79:605-621.

Kelso S, Ganong AH, Brown TH (1986) Hebbian synapses in hippocampus. Proc Natl Acad Sci USA 83:2326-2330.

Kiehn O (1991) Plateau potentials and active integration in the "final common pathway" for motor behavior. Trends Neurosci 14:68-73.

Kramer RH, Levitan IB (1990) Activity-dependent neuromodulation in Aplysia neuron R15: intracellular calcium antagonizes neurotransmitter responses mediated by cAMP. J Neurophysiol 63:1075-1088.

Lechner HA, Byrne JH (1998) New perspectives on classical conditioning: a synthesis of Hebbian and non-Hebbian mechanisms. Neuron 20:355-358.

Lechner HA, Baxter DA, Clark JW, Byrne JH (1996) Bistability and its regulation by serotonin in the endogenously bursting neuron R15 in Aplysia. J Neurophysiol 75:957-962.

Llinas R (1988) The intrinsic electrophysiological properties of mammalian neurons: insights into central nervous system function. Science 242:1654-1664.

Llinas R, Yarom Y (1986) Oscillatory properties of guinea pig inferior olivary neurones and their pharmacological modulation: an in vitro study. J Physiol (Lond) 376:163-182.

Mackintosh NJ (1974) The psychology of animal learning. London: Academic.

Marder E, Calabrese RL (1996) Principles of rhythmic motor pattern generation. Physiol Rev 76:687-717.

Marder E, Abbott LF, Turrigiano GG, Liu Z, Golowasch J (1996) Memory from the dynamics of intrinsic membrane currents. Proc Natl Acad Sci USA 93:13481-13486.

McCormick DA (1989) Cholinergic and noradrenergic modulation of thalamocortical processing. Trends Neurosci 12:215-221.

Morton DW, Chiel HJ (1993) In vivo buccal nerve activity that distinguishes ingestion from rejection can be used to predict behavioral transitions in Aplysia. J Comp Physiol [A] 172:17-32.

Mowrer RR, Klein SB (1989) A contrast between traditional and contemporary learning theory. In: Contemporary learning theories (Klein SB, Mowrer RR, eds), pp 1-10. Hillsdale, NJ: LEA.

Murphy GG, Glanzman DL (1997) Mediation of classical conditioning in Aplysia californica by long-term potentiation of sensorimotor synapses. Science 278:467-471.

Nargeot R, Baxter DA, Byrne JH (1995) Afferent control of buccal motor programs in Aplysia. Soc Neurosci Abstr 21:1766.

Nargeot R, Baxter DA, Byrne JH (1997a) Dynamic recruitment of neurons into the central pattern generator $(\mathrm{CPG})$ for feeding is associated with motor pattern selection in Aplysia. Soc Neurosci Abstr 23:1046.

Nargeot R, Baxter DA, Byrne JH (1997b) Contingent-dependent enhancement of rhythmic motor patterns: an in vitro analog of operant conditioning. J Neurosci 17:8093-8105.

Nargeot R, Baxter DA, Byrne JH (1998) Contingent reinforcement in an analogue of operant conditioning modified the intrinsic membrane properties of an identified Aplysia neuron (B51). Soc Neurosci Abstr 24:1890.

Nargeot R, Baxter DA, Byrne JH (1999a) In vitro analog of operant conditioning in Aplysia. I. Contingent reinforcement modifies the functional dynamics of an identified neuron. J Neurosci 19:2247-2260.

Nargeot R, Baxter DA, Patterson GW, Byrne JH (1999b) Dopaminergic synapses mediate neuronal changes in an analogue of operant conditioning. J Neurophysiol, in press.

Nowak L, Bregestovski P, Ascher P, Herbet A, Prochiantz A (1984) Magnesium gates glutamate-activated channels in mouse central neurones. Nature 307:462-465.

Ocorr KA, Walters ET, Byrne JH (1985) Associative conditioning analog selectively increases cAMP levels of tail sensory neurons in Aplysia. Proc Natl Acad Sci USA 82:2548-2552.

Plummer MR, Kirk MD (1990) Premotor neurons B51 and B52 in the buccal ganglia of Aplysia californica: synaptic connections, effect on ongoing motor rhythms, and peptide modulation. J Neurophysiol 63:539-558.

Raymond JL, Baxter DA, Buonomano DV, Byrne JH (1992) A learning rule based on empirically-derived activity-dependent neuromodulation supports operant conditioning in a small network. Neural Networks 5:789-803.

Rescorla RA (1987) A Pavlovian analysis of goal-directed behavior. Am Psychol 42:119-129.

Russell DF, Hartline DK (1978) Bursting neural networks: a reexamination. Science 200:453-456.

Russo RE, Hounsgaard J (1996) Plateau generating neurones in the dorsal horn in an in vitro preparation of the turtle spinal cord. J Physiol (Lond) 493:39-54.

Skinner BF (1938) The behavior of organisms: an experimental analysis. New York: Appleton-Century-Crofts.

Skinner BF (1966) The phylogeny and ontogeny of behavior: contingencies of reinforcement throw light on contingencies of survival in the evolution of behavior. Science 153:1205-1213.

Skinner BF (1981) Selection by consequences. Science 213:501-504.

Stein L, Belluzzi JD (1989) Cellular investigations of behavioral reinforcement. Neurosci Biobehav Rev 13:69-80.

Steriade M, McCormick DA, Sejnowski TJ (1993) Thalamocortical oscillations in the sleeping and aroused brain. Science 262:679-685.

Susswein AJ, Byrne JH (1988) Identification and characterization of neurons initiating patterned neural activity in the buccal ganglia of Aplysia. J Neurosci 8:2049-2061.

Susswein AJ, Kabotyanski EA, Hurwitz I, Sakharov DA (1993) Catecholaminergic neurons in the esophagus of Aplysia: a peripheral brain? Soc Neurosci Abstr 19:350.

Thorndike EL (1933) A proof of the law of effect. Science 77:173-175.

Tolman EC (1949) There is more than one kind of learning. Psychol Rev 56:144-155.

Turrigiano G, Abbott LF, Marder E (1994) Activity-dependent changes in the intrinsic properties of cultured neurons. Science 264:974-977.

Vaccarino FJ, Schiff BB, Glickman SE (1989) Biological view of reinforcement. In: Contemporary learning theories (Klein SB, Mowrer RR, eds), pp 111-142. Hillsdale, NJ: LEA.

Walters ET, Byrne JH (1983) Associative conditioning of single sensory neurons suggests a cellular mechanism for learning. Science 219:405-408.

Walters ET, Byrne JH (1985) Long-term enhancement produced by activity-dependent modulation of Aplysia sensory neurons. J Neurosci 5:662-672.

Wolpaw JR (1987) Operant conditioning of primate spinal reflexes: the H-reflex. J Neurophysiol 57:443-459.

Woollacott M, Hoyle G (1977) Neural events underlying learning in insects: changes in pacemaker. Proc R Soc Lond B Biol Sci 195: 395-415. 